\title{
Delivery in water, experiences in a population of Mexican women in Mexico City
}

\begin{abstract}
Background: Labor is a physiological process during which the fetus, the membranes, the umbilical cord and the placenta are expelled from the uterus and water delivery has become popular, although its prevalence is unknown, it is supported by healthy women with fullterm pregnancies, without complications; although there is insufficient evidence to support or discourage it.
\end{abstract}

Objective: To identify obstetric and neonatal outcomes and complications in women who delivered in water and to compare them with traditional deliveries.

\begin{abstract}
Material and methods: It is a retrospective, observational and cross-sectional study, where 2486 women were included from a database of 4223 women assisted from 2004 to 2020 in private hospitals; Of the 2486 patients included, 1025 had a water delivery and 1461 had a conventional delivery, discarding 1737 women who underwent caesarean section from the study. The information obtained from the patients, their data obtained for this study were kept in the anonymity of the patients, where they were analyzed: non-parametric data reported in percentages using Chi square; Parametric, perinatal and neonatal data are reported as mean plus standard deviation $( \pm \mathrm{SD})$ and analyzed using Student's T, using the SPSS version 25 statistical package.
\end{abstract}

Results: A total of 2486 women were included in this study, the birth in 1025 was water delivery (24\%) and 1461 was conventional delivery (35\%), 1737 caesarean section (41\%) were excluded from the study, no difference was observed maternal age; unlike weight, height, body mass index; they were higher in women with water birth compared to conventional. No difference was demonstrated between nulliparous $(45.99 \%)$ and multiparous $(53.86 \%)$ when comparing both birth in water and conventional; only increase in previous caesarean sections $(9.36$ vs $6.5 \%, \mathrm{p}=0.008)$ and decrease in previous abortions ( 16.19 vs $20.94 \%, p=0.002)$ in water delivery with the conventional one; complications were not different: administration of oxytocin (3.2 vs 3.1) or postpartum hemorrhage $(0.29$ vs 0.13 ) in both deliveries; no differences in first degree perineal tears (21.4 vs $18.5 \%)$.

Conclusion: Water birth reduces stress, pain sensation, second and third degree perineal lacerations and contributes to better newborn outcomes; the selection and inclusion of patients with low-risk pregnancies allows better perinatal results than conventional delivery; but, further studies are required to use it routinely.
Volume I 3 Issue I - 2022

Luján-Irastorza Jesús Estuardo,' DurandMontaño Carlos,' Hernández-Ramos Roberto,' Ávila-Pérez Felipe de Jesús,' Ávila-Rebollar Daniela,' Kava Braverman Alejandro,' Guerrero Vargas José Juan,' Valdez-Chávez Teresita de Jesús,' SilvaMeléndez Jorge, ' Yáñez-González Marco Antonio,' García-Cruz Valeria,' Loof-Esquivel Mónica,' Beltrán-Tapia José Luis,' PeñalvaRosales Samuel Octavio,' 'Vargas-Hernández Víctor Manuel ${ }^{2}$

'PRONATAL Clinic (Bité Médica Hospital), Mexico

${ }^{2}$ Women's Health Clinic, Mexico

Correspondence: Vargas Hernández Victor Manuel, Gynecologic Department, UNAM, Women's Health Clinic, Mexico, Tel 5552179783, Fax 5555746647, Email vvargashernandez@yahoo.com.mx Luján Irastorza Jesús Estuardo, PRONATAL Clinic (Bité Médica Hospital), Mexico,Tel 5521292609, Email jlujan05@hotmail.com

Received: December 14, 202I | Published: January 05, 2022

\section{Background}

Labor is a physiological process during which the fetus, membranes, umbilical cord, and placenta are expelled from the uterus. The initial evaluation of labor should include a review of the patient's prenatal care, including confirmation of the estimated date of delivery.

Water delivery during labor or delivery has become popular in recent decades, although its prevalence is unknown ${ }^{1}$ due to the lack of reports, even lack of records in birth certificates and varies according to cultural factors ${ }^{2,3}$ that vary from $1.5 \%$ in hospitals to $58 \%$ in independent clinics; ${ }^{2,4}$ although, it relies on healthy women with full-term pregnancies, without complications having their labor and delivery in water; ;,6 there is insufficient high-quality evidence to support or discourage it. ${ }^{7}$

Labor or water delivery often does not have a uniform definition; This is generally known as "water birth," but the effects and results may be different for immersion during the first stage of labor and the second stage, including delivery. By distinguishing data and related outcomes separately during the first from second stages of labor and delivery. Not all studies identify them, considering the results for all women together, in the first and second stages of labor and delivery. ${ }^{2,8}$
Safety or risk in association with labor in water translates into results equivalents in a different stage of labor; specifically, the results during the first stage of labor may not be the same as the results associated with underwater birth. ${ }^{1,2,8-12}$

Conditions vary between retrospective, observational, prospective, and randomized clinical trials. Retrospective studies, often reporting single-center data, cannot demonstrate causal relationships between observed outcomes and exposure to water labor. Retrospective and prospective observational studies categorize outcomes, including stage 2 through water calving, according to actual exposures (rather than predicted) at immersion. ${ }^{4.9,11,13-15,17}$

Most studies consider only healthy women with singleton pregnancies with cephalic presenting fetuses as candidates for water birth, limits the generalizability of results. ${ }^{2,8,10,18}$

During the first stage of water labor, it was associated with a decrease in the use of epidural, spinal or paracervical analgesia in women for water delivery compared to controls; there was a reduction in the duration of the first stage of labor, there were no differences in the incidence or severity of perineal trauma, including third and fourth degree lacerations, and episiotomy or caesarean section. No 
benefit was reported for the newborn during labor or water delivery, ${ }^{10}$ the outcomes of the newborns in the second stage and birth after immersion in water were compared with conventional birth; did not show neonatal benefits associated with water delivery ${ }^{18}$ and the evidence is insufficient to rule out this possibility, ${ }^{19}$ they do not describe a higher prevalence of adverse maternal outcomes. The available evidence does not suggest an increased risk of adverse maternal outcomes during labor and delivery in water, this conclusion is not diminished by the lack of data on rare serious outcomes such as severe morbidity and mortality.

No greater frequency of adverse neonatal outcomes was found ${ }^{18,19}$ with regard to morbidity and mortality, it was concluded that "there is insufficient evidence on the use of immersion in water during the second stage of labor and it cannot be established clear implications"10 mortality and morbidity data were limited, including data on cord avulsion, water aspiration, and hyponatremia, without drawing firm conclusions due to heterogeneity of results, ${ }^{18}$ although underwater births were not associated with increased harm to newborns, the existing evidence is insufficient to rule out the possibility of additional rare but serious adverse outcomes. ${ }^{19}$

If the physician believes, based on the evidence, that second stage immersion and labor while submerged would be detrimental to the overall health and well-being of the woman or fetus, he should not perform such labor. ${ }^{20}$

The American College of Obstetricians and Gynecologists (ACOG) makes the following recommendations: Water immersion during the first stage of labor may be associated with shorter labor and less use of spinal and epidural analgesia and may be offered to healthy women with uncomplicated full-term pregnancies. There are insufficient data to draw conclusions about benefits and risks during the second stage of labor and delivery; it is recommended that the birth is not in water. The woman who requests water delivery should be informed about the benefits and risks of the mother and the perinatal, it is not studied enough to support or discourage it; Rare but serious neonatal complications associated with this choice should be reported. Prospective studies on maternal and perinatal benefits and risks associated with waterborne labor and delivery are not precluded. Facilities during labor and water delivery must establish rigorous protocols for the selection of candidates; maintenance and cleaning of bathtubs and tubs or swimming pools; infection control procedures and personal protective equipment for health care personnel; monitoring of women and fetuses at appropriate intervals while submerged; and removing women from the water if urgent maternal or fetal concerns or complications arise. ${ }^{21}$

\section{Material and method}

Retrospective, observational and cross-sectional study, which included 2486 women who were part of a database of 4223 women. They carried out their pregnancy monitoring at the PRONATAL clinic (Interior of Hospital Bíte Médica, Mexico City) and had their delivery at Hospital Médica Sur Lomas, between 2004 and 2012 and Hospital Bité Médica, between 2013 and 2020. Of the 2486 patients included, 1025 had a water delivery and 1461 had a conventional delivery, discarding 1737 women who had caesarean delivery from the study.

Inclusion criteria: Patients of reproductive age, low-risk pregnant patients, patients with a single pregnancy, water and conventional deliveries, spontaneous pregnancies and by assisted reproductive techniques (ART), with a history of 2 or less caesarean sections, with a history of 1 or more abortions.
Exclusion criteria: The information obtained from the patients was retrospectively collected from the notebooks provided by the (Labor, delivery and resuscitation) of the Bité Médica hospital and from the digital records of the PRONATAL Clinic, obtaining anthropometric data (Mother: age, weight and height), delivery results (weeks of gestation, perineal tear, nulliparous, multiparous, caesarean sections and abortions) and neonatal data (Newborn: Weight, height, Apgar at minute 1 and 5).

The data obtained to carry out this study were handled with discretion and the anonymity of the patients was maintained. The data obtained will be analyzed in 2 ways: non-parametric data are reported in percentages and were analyzed using "Chi square" (perineal lacerations, epidural block, oxytocin, nulliparous, multiparous, caesarean sections and previous abortions), and 2) parametric data [Mother: age, weight, height, gestation weeks and body mass index (BMI), and baby perinatal data: weight, height and APGAR] are reported as mean plus standard deviation $(\bar{X} \pm \mathrm{SD})$ and are analyzed using "T student", Using the statistical package SPSS version 25.

\section{Results}

A total of 2486 women were included in this study, among whom 1025 were waterborne $(24 \%)$ and 1461 were conventional delivery (35\%), additionally, 1737 women who had caesarean delivery (41\%) were excluded from the study (Figure 1).

\section{PREVALENCE OF TYPE OF DELIVERY (2004-2020)}

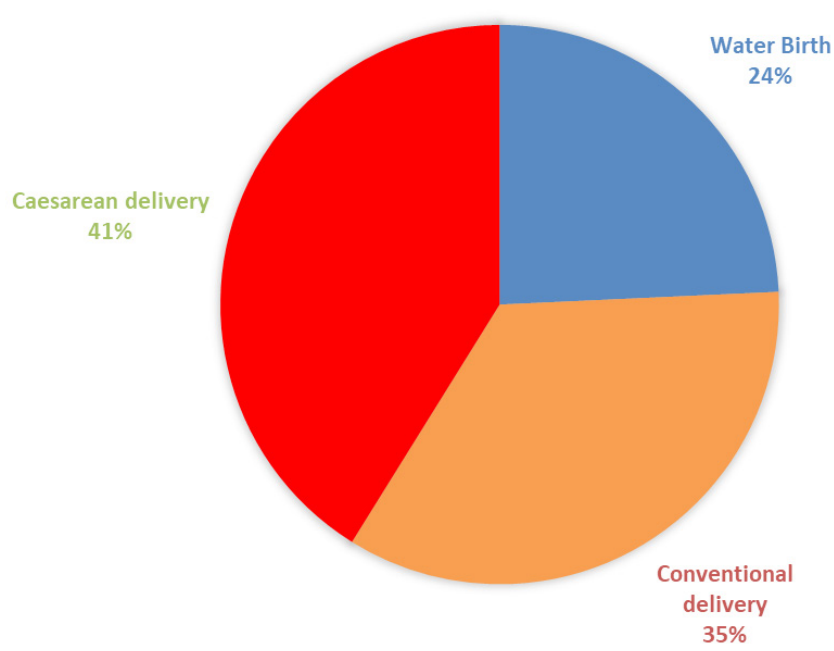

Figure I Shows prevalence of water delivery, conventional delivery and caesarean delivery.

Within the maternal data, no difference in age is observed when comparing water delivery vs conventional delivery (33.6 vs 33.3 years), unlike weight ( $67.07 \pm 9.8$ vs $61.2 \pm 10.5 \mathrm{~kg}, \mathrm{p}=0.05)$, height $(1.65 \pm 0.06$ vs $1.62 \pm 0.05, \mathrm{p}=0.02)$ and BMI $(24.4 \pm 3.7$ vs $23.07 \pm 3.5$, $\mathrm{p}=0.001$ ), which showed an increase in the water calving group compared to the conventional calving group. Regarding the history of previous pregnancies, no difference was shown between nulliparous patients (44.8 vs $45.99 \%$ ) and multiparous (55.02 vs $53.86 \%$ ) when comparing the water delivery group against the conventional delivery group. They only showed an increase in previous caesarean sections ( 9.36 vs $6.5 \%, p=0.008)$ in water delivery when compared with conventional delivery and a decrease in previous abortions (16.19 vs $20.94 \%, p=0.002)$ in the water delivery group when compared with childbirth (Conventional) (Table 1). 
Table I Shows anthropometric data of the mother, as well as history of previous pregnancies, neonatal data of the newborn and results obtained from the water and conventional birth

\begin{tabular}{|c|c|c|c|}
\hline & Water birth & Conventional delivery & $\mathbf{P}$ \\
\hline$n$ & 1025 & $|46|$ & \\
\hline \multicolumn{4}{|l|}{ Maternal } \\
\hline Age $(\bar{X} \pm \mathrm{DE})$ & $33.6 \pm 4$ & $33.3 \pm 4.1$ & 0.3 \\
\hline Weight ( $\bar{X} \pm \mathrm{DE})$ & $67.07 \pm 9.8$ & $61.2 \pm 10.5$ & $0.05 *$ \\
\hline Size $(\bar{X} \pm \mathrm{DE})$ & $1.65 \pm 0.06$ & $1.62 \pm 0.05$ & $0.02 *$ \\
\hline $\mathrm{BMI}(\bar{X} \pm \mathrm{DE})$ & $24.4 \pm 3.7$ & $23.07 \pm 3.5$ & $0.001 *$ \\
\hline Gestation week $(\bar{X} \pm \mathrm{DE})$ & $38.8 \pm 1.3$ & $38.9 \pm 9.3$ & 0.5 \\
\hline Nulliparous & $44.87 \%(460 / 1025)$ & $45.99 \%(672 / 146 I)$ & 0.5 \\
\hline Multiparous & $55.02 \%(564 / 1025)$ & $53.86 \%(787 / 1461)$ & 0.5 \\
\hline Previous caesarean $\leq 2$ & $9.36 \%(96 / 1025)$ & $6.5 \%(95 / 1461)$ & $0.008 *$ \\
\hline Previous abortion $\geq 1$ & $16.19 \%(166 / 1025)$ & $20.94 \%(306 / 1461)$ & $0.002 *$ \\
\hline Oxytocin & $3.2 \%(33 / 1025)$ & $3.1 \%(46 / 1461)$ & 0.9 \\
\hline Hemorrhage & $0.29 \%(3 / 1025)$ & $0.13 \%(2 / 1461)$ & 0.3 \\
\hline \multicolumn{4}{|l|}{ Perineal laceration } \\
\hline Ist grade & $21.4 \%(220 / 1025)$ & $\mid 8.5 \%(27|/| 46 \mid)$ & 0.3 \\
\hline 2nd grade & $6.6 \%(68 / 1025)$ & II.4\% (I67/I46I) & $0.00 *$ \\
\hline 3 rd grade & $0 \%(0 / 1025)$ & $2.8 \%(4 I / \mid 46 I)$ & NA \\
\hline Epidural block & $1.9 \%(20 / 1025)$ & $53.1 \%(776 /|46|)$ & $0.00 *$ \\
\hline \multicolumn{4}{|l|}{ Neonate } \\
\hline Weight ( $\bar{X} \pm \mathrm{DE})$ & $3067.4 \pm 359.9$ & $3059.7 \pm 435.2$ & $0.02 *$ \\
\hline Size $(\bar{X} \pm \mathrm{DE})$ & $49.27 \pm 1.8$ & $49.2 \pm 1.8$ & 0.1 \\
\hline OFF Im ( $\bar{X} \pm \mathrm{DE})$ & $8.9 \pm 0.3$ & $9 \pm 3.4$ & 0.4 \\
\hline OFF $5 \mathrm{~m}(\bar{X} \pm \mathrm{DE})$ & $9.62 \pm 0.4$ & $9.5 \pm 0.5$ & $0.00 *$ \\
\hline
\end{tabular}

* Statistical difference when comparing Water birth vs Conventional delivery. Chi square and Student's t. In both cases, $p \geq 0.05$ was considered

In the complications that occurred during delivery, there was no significant difference in the application of oxytocin (3.2 vs 3.1$)$ and in the presence of hemorrhage ( 0.29 vs 0.13 ) between the water delivery group and conventional delivery. Regarding perineal lacerations: first degree, they have no significant difference (21.4 vs $18.5 \%$ ) when comparing water delivery vs conventional delivery, second degree, presents a statistically significant increase in conventional delivery when comparing with water delivery ( 6.6 vs $11.4 \%, \mathrm{p}=0.00)$ and third degree, presents an increase in conventional delivery compared to water delivery ( 0 vs $2.8 \%$ ), additionally, $1.9 \%$ of water deliveries underwent epidural blockage and ended in conventional delivery (Table 1).

Regarding the perinatal data, the weight of the babies was statistically higher in the water delivery group compared to the conventional delivery group $(3067.4 \pm 359.9$ vs $3059.7 \pm 435.2 \mathrm{~g}$, $\mathrm{p}=0.02$ ), unlike the height of the babies. babies, who did not present a difference in water delivery when compared with conventional delivery $(49.27 \pm 1.8$ vs $49.2 \pm 1.8 \mathrm{~cm})$. Finally, water calving and conventional calving did not present a significant difference in APGAR in the first minute ( $8.9 \pm 0.3$ vs $9 \pm 3.4)$ in contrast to minute 5 , in which there is an increase in APGAR at 5 minutes in water calving. when comparing with conventional delivery $(9.62 \pm 0.4$ vs $9.5 \pm 0.5$, $\mathrm{p}=0.00$ ) (Table 1).

\section{Discussion}

Obstetricians have divided labor into 3 stages that outline milestones in a continuous process; first stage of labor, begins with regular uterine contractions and ends with complete cervical dilation at $10 \mathrm{~cm}$, divided into latent phase and active phase; the latent phase begins with mild and irregular uterine contractions that soften and shorten the cervix; the contractions become progressively more rhythmic and stronger, the active phase generally begins around $3-4 \mathrm{~cm}$ of cervical dilation and is characterized by rapid cervical dilation and descent of the presenting fetal part. Second stage of labor; It begins with a full cervical dilation and ends with the delivery of the fetus. ${ }^{22}$ Third stage of labor, period between delivery of the fetus and delivery of the placenta and fetal membranes, ${ }^{23}$ which are accompanied by pain, which differs from person to person and can be influenced by physical, psychological and cultural conditions. ${ }^{24-27}$ To assess the effects of water immersion (water birth) during labor or delivery (first, second and third stages of labor) in women and their newborns. 
Many women choose to work and give birth in water (water immersion) and this practice is becoming more popular in many countries, particularly in midwifery-led units. Therefore, it is important to understand more about the benefits of water immersion during labor and delivery for women and their newborns, along with the risks.

It is important to examine whether immersion in water during the first and/or second stage of labor has the potential to maximize women's ability to manage labor pain and have a normal delivery without increasing the risk of an adverse (harmful) event. Adverse events may pose an increased risk of infection for women and/or their newborns; a greater chance of a severe tear of the perineum (the area between the anus and the vagina), and can make it difficult to estimate blood loss in the event of bleeding. When evaluating benefits, we consider wellness to encompass both physical and psychological health.

Immersion in water during early labor will likely result in fewer women having an epidural, but it likely makes little or no difference to the number of women who have a normal vaginal delivery, instrumental delivery, caesarean section, or a severe perineal tear. We are uncertain about the effect on the amount of blood lost after birth because the quality of the evidence was very low. Water labor can also make little or no difference for babies to enter the neonatal intensive care unit or develop infections. No stillbirths or infant deaths were reported.

In healthy women at low risk of complications, there is moderate to low-quality evidence that immersion in water during early labor probably has little effect on mode of delivery or perineal trauma, but may reduce the use of regional analgesia. The evidence of immersion during the second stage of labor is limited and shows no clear differences in maternal or neonatal outcomes in intensive care. There is no evidence of increased adverse effects to the fetus/newborn or woman from labor or delivery in water. The available evidence is limited by clinical variability and heterogeneity between trials, and no specialist-designed studies have been performed.

While the changes that occur during pregnancy are slow and gradual, childbirth generates bodily changes that are intense and abrupt, which are accompanied by pain, which differs from person to person and can be influenced by physical, psychological and cultural conditions. ${ }^{24-29}$ On the other hand, anxiety and fear can increase plasma concentrations of catecholamines, which is associated with enervated uterine contractility, which leads to women with severe fear of childbirth increasing their nociceptive stimuli and the perception of pain is magnified. In fact, prenatal fears have been seen to complicate and prolong labor, increase the intensity of pain, leading to a negative experience on the part of the mother. ${ }^{18,21,25}$

Considering the physiological changes associated with childbirth, different methods with minimal intervention, medication and low incidence of complications for both the mother and the newborn have been investigated in a large number of studies. It is the case of water delivery that has a prevalence in this study of $24 \%$, Figure 1 , where studies have reported a decrease in antispasmodic drugs, analgesics and opioids, compared to conventional delivery. ${ }^{18,21}$ Because relaxation of the mother's body is generated, resulting in decreased pain during labor. ${ }^{30-33}$ Similarly, in this study there was a greater number of women who gave birth by water delivery compared to conventional delivery, who were able to complete the expulsion of the baby and the placenta, without the application of epidural block (98.1 vs $46.9 \%$, $\mathrm{p}=0.00$ ) (Table 1). Another benefit observed in water birth compared to conventional birth is the decrease in perineal lacerations, as shown by Da Costa J. 2019, who report that water birth has a protective effect against third degree perineal lacerations ( 0 vs $19.4 \%) .^{40}$

Similarly, this study showed a statistically significant decrease in second degree perineal lacerations (6.6 vs $11.4 \%, \mathrm{p}=0.00)$ and third degree (0 vs $2.8 \%)$ in women who had water birth when compared to those who had Conventional delivery (Table 1). Within our results, we observed no difference in the presence of bleeding $(0.9 \mathrm{vs} 0.13 \%)$, between the water delivery group and the conventional delivery group (Table 1).

found no difference in the prevalence of bleeding among women with water birth compared with conventional birth. ${ }^{29}$ In water childbirth studies report decreased release of stress hormones such as catecholamines compared to conventional delivery, allowing more efficient release of oxytocin and labor progression, $, 6,8,20,34$ due to reducing anxiety, pain, physiological stress and psychological. ${ }^{32}$ In addition to this, in this work, no difference was found in the application of oxytocin in water delivery when compared to conventional delivery (3.2 vs $3.1 \%$ ) (Table 1 ).

The women who decided to have a water birth in this study had greater weight $(67.07 \pm 9.8$ vs $61.2 \pm 10.5, \mathrm{p}=0.05)$ and height ( $1.65 \pm 0.06$ vs $1.62 \pm 0.05, \mathrm{p}=0.02)$ compared to those who decided to give birth conventional. None of the groups presented high levels of BMI (24.4 \pm 3.7 vs $23.07 \pm 3.5, \mathrm{p}=0.001)$ (Table 1$)$, coinciding with studies where the preference for water delivery was higher in women with BMI less than 30 due to complications that can occur in obese women. ${ }^{35-41}$

Regarding neonatal data, the weight of babies at birth was higher in water delivery compared to conventional delivery $(3067.4 \pm 359.9$ vs $3059.7 \pm 435.2, \mathrm{p}=0.02)$, in turn, the APGAR in minute 1 did not present significant difference between water and conventional calving ( $8.9 \pm 0.3$ vs $9 \pm 3.4)$, unlike APGAR in minute $5(9.62 \pm 0.4$ vs $9.5 \pm 0.5$, $\mathrm{p}=0.00$ ), which was greater in water calving compared to conventional calving (Table 1); different from that reported, ${ }^{42-44}$ who report similar APGAR values at minute 1 and 5 , between water and conventional delivery.

This work provides information to support women's right to access medically supported and non-pharmacological pain relief options during labor only if needed. Coinciding with studies that suggest that water delivery is a factor that drives the improvement of the delivery experience..$^{21,27,45,46}$ Regarding the decision to deliver in water, decision-making is often limited by lack of access to hydrotherapy tubs, access to intermittent auscultation as a primary form of fetal surveillance, and lack of screening tests. standardized to establish births with low medical risk, which were the main inclusion criteria in this work for water births.

\section{Conclusion}

Water delivery reduces stress generated during childbirth and in return, causes women in labor to perceive less pain. In addition, it helps to reduce the possibility of second and third degree perineal tearing. The decrease in pain, generated during water delivery, contributes to a better APGAR score at minute 5 .

The selection and inclusion of patients with low-risk pregnancies makes it possible to avoid complications during water delivery, allowing better perinatal outcomes than in conventional delivery.

Water delivery could be used as a routine during childbirth if a properly designed methodology is applied and if it is carried out in suitable conditions, both for the mother and the newborn. 


\section{Acknowledgments}

None.

\section{Funding}

None.

\section{Conflicts of interest}

The authors report no conflict of interest.

\section{References}

1. Bovbjerg ML, Cheyney M, Everson C. Maternal and newborn outcomes following waterbirth: the midwives alliance of North America statistics project, 2004 to 2009. Cohort J Midwifery Womens Health. 2016;61(1):11-20.

2. Lukasse $\mathrm{M}$, Rowe $\mathrm{R}$, Townend $\mathrm{J}$, et al. Immersion in water for pain relief and the risk of intrapartum transfer among low risk nulliparous women: secondary analysis of the Birthplace national prospective cohort study. BMC Pregnancy Childbirth. 2014;14:60.

3. Liu Y, Liu Y, Huang X, et al. A comparison of maternal and neonatal outcomes between water immersion during labor and conventional labor and delivery. BMC Pregnancy Childbirth. 2014;14:160.

4. Otigbah CM, Dhanjal MK, Harmsworth G, et al. A retrospective comparison of water births and conventional vaginal deliveries. Eur $J$ Obstet Gynecol Reprod Biol. 2000;91(1):15-20.

5. Midwifery care in labor guidance for all women in all settings. Royal College of Midwives. Midwifery Blue Top Guidance No.1 Nov 2018.

6. American College of Nurse-Midwives. Hydrotherapy during labor and birth: Division of Standards and Practice, Clinical Documents Section Approved by the ACNM Board of Directors: April 2014.

7. National Institute for Health and Care Excellence. Intrapartum care for healthy women and babies. Clinical guideline. 2014.

8. Burns EE, Boulton MG, Cluett E, et al. Characteristics, interventions, and outcomes of women who used a birthing pool: a prospective observational study. Birth. 2012;39(3):192-202.

9. Geissbuehler V, Stein S, Eberhard J. Waterbirths compared with landbirths: an observational study of nine years. J Perinat Med. 2004;32(4):308-314.

10. Cluett ER, Burns E, Cuthbert A. Immersion in water during labor and birth. Cochrane Database Syst Rev. 2018;5(5):CD000111.

11. Henderson, J., Burns, EE, Regalia, AL et al. Laboring women who used a birthing pool in obsteric units in Italy: prospective observational study. BMC Pregnancy Childbirth. 2014;14:17.

12. Thoeni A, Zech N, Moroder L, et al. Review of 1600 water births. Does water birth increase the risk of neonatal infection? J Matern Fetal Neonatal Med. 2005;17(5):357-361.

13. Gilbert RE, Tookey PA. Perinatal mortality and morbidity among babies delivered in water: surveillance study and postal survey. $B M J$. 1999;319(7208):483-487.

14. Carpenter L, Weston P. Neonatal respiratory consequences from water birth. J Paediatr Child Health. 2012;48(5):419-423.

15. Dahlen HG, Dowling H, Tracy M, et al. Maternal and perinatal outcomes amongst low risk women giving birth in water compared to six birth positions on land. A descriptive cross sectional study in a birth center over 12 years. Midwifery. 2013;29(7):759-764.

16. Ulfsdottir H, Saltvedt S, Georgsson S. Waterbirth in Sweden - a comparative study. Acta Obstet Gynecol Scand. 2018;97(3):341-348.

17. Zanetti-Daellenbach RA, Tschudin S, Zhong XY, et al. Maternal and neonatal infections and obstetrical outcome in water birth. Eur $J$ Obstet Gynecol Reprod Biol. 2007;134(1):37-43.
18. Davies R, Davis D, Pearce M, et al. The effect of waterbirth on neonatal mortality and morbidity: a systematic review and meta-analysis. JBI Database System Rev Implement Rep. 2015;13(10):180-231.

19. Taylor H, Kleine I, Bewley S, et al. Neonatal outcomes of waterbirth: a systematic review and meta-analysis. Arch Dis Child Fetal Neonatal Ed. 2016;101(4):F357-F365.

20. ACOG Committee Opinion No. 578: Elective surgery and patient choice. Obstet Gynecol. 2013;122(5):1134-1138.

21. Committee Opinion No. 679. Immersion in water during labor and delivery. American College of Obstetricians and Gynecologists. Obstet Gynecol. 2016;128:231-236.

22. Romero Lecha, Sergio Pascual. Aquatic delivery: most relevant complications and benefits compared to conventional vaginal delivery. Integrative Review. Agora de salut. 2018;5:289-298.

23. Cortes E, Basra R, Kelleher CJ. Waterbirth and pelvic floor injury: a retrospective study and postal survey using ICIQ modular long form questionnaires. Eur J Obstet Gynecol Reprod Biol. 2011;155(1):27-30.

24. Beigi NM, Broumandfar K, Bahadoran P, et al. Women's experience of pain during childbirth. Iran J Nurs Midwifery Res. 2010;15(2):77-82.

25. Yongfang Deng, Yan Lin, Liyuan Yang, et al. A comparison of maternal fear of childbirth, labor pain intensity and intrapartum analgesic consumption between primiparas and multiparas: A cross-sectional study. International Journal of Nursing Sciences. 2021;8(4):380-387.

26. Sidebottom A, Vacquier M, Simon K, et al. Maternal and neonatal outcomes in hospital-based deliveries with water immersion. Obstet Gynecol. 2020;136(4):707-715.

27. Vanderlaan J, Hall PJ, Lewitt M. Neonatal outcomes with water birth: A systematic review and meta-analysis. Midwifery. 2018;59:27-38.

28. Guidelines for water immersion and water birth. Arizona Department of Healt Services November 2016.

29. Maude, RM, Kim, M. Getting into the water: a prospective observational study of water immersion for labor and birth at a New Zealand District Health Board. BMC Pregnancy Childbirth. 2020;20:312.

30. Carvalho B, Zheng M, Aiono-Le Tagaloa L. A prospective observational study evaluating the ability of prelabor psychological tests to predict labor pain, epidural analgesic consumption, and maternal satisfaction. Anesth Analg. 2014;119(3):632-640.

31. Lang AJ, Sorrell JT, Rodgers CS, et al. Anxiety sensitivity as a predictor of labor pain. Eur J Pain. 2006;10(3):263-270.

32. Klusman LE. Reducation of pain in childbirth by the alleviation of anxiety during pregnancy. J Consult Clin Psychol. 1975;43(2):162-165.

33. Chaichian S, Akhlaghi A, Rousta F, et al. Experience of water birth delivery in Iran. Arch Iran Med. 2009;12(5):468-471.

34. Shaw-Battista J. Systematic review of hydrotherapy research: does a warm bath in labor promote normal physiologic childbirth? J Perinat Neonatal Nurs. 2017.

35. Neiman E, Austin E, Tan A, et al. Outcomes of waterbirth in a US hospitalbased midwifery practice: a retrospective cohort study of water immersion during labor and birth. J Midwifery Womens Health. 2020;65(2):216-223.

36. Cammu H, Clasen K, Van Wettere L, et al. To bathe or not to bathe' during the first stage of labor. Acta Obstet Gynecol Scand. 1994;73(6):468-472.

37. Simkin P, O Hara M, Nonpharmacologic relief of pain during labor: Systematic reviews of five methods. Am J Obstet Gynecol. 2002;186:S131-S159.

38. Carlsson T, Ulfsdottir $\mathrm{H}$, Waterbirth in low-risk pregnancy: An exploration of women's experiences. $J$ Adv Nurs. 2020;76(5):1221-1231.

39. Meyer SL, Weible CM, Woeber K. Perceptions and practice of waterbirth: a survey of Georgia midwives. J Midwifery Womens Health. 2010;55(1): $55-59$. 
40. Da Costa J, Varela V, Marçal F, et al. Perineal outcomes and its associated variables of water births versus non-water births: a cross-sectional study. Rev Bras Saude Mater Infant. 2019;19(4):777-786.

41. Snapp C, Stapleton SR, Wright J, et al. The Experience of land and water birth within the american association of birth centers perinatal data registry 2012-2017. J Perinat Neonatal Nurs. 2020;34(1):16-26.

42. Gayiti MR, Li XY, Zulifeiya AK, et al. Comparison of the effects of water and traditional delivery on birthing women and newborns. Eur Rev Med Pharmacol Sci. 2015;19(9):1554-1558.

43. Camargo JCS, Varela V, Ferreira FM, et al. The Waterbirth project: são bernardo hospital experience. Women Birth. 2018;31(5):e325-e333.
44. Rosales S, Ortiz E, Alarcón D, et al. A retrospective study of maternal and neonatal outcomes following conventional and water birth in Ecuador. Global Journal of Health Science. 2017;9(4):1-8.

45. Demirel G, Moraloglu O, Celik H, et al. The effects of water birth on neonatal outcomes: a five-year result of a referral tertiary center. European Review for Medical and Pharmacological Sciences. 2013;17:1395-1398.

46. Clews C, Church S, Ekberg M. Women and waterbirth: A systematic meta-synthesis of qualitative studies. Women Birth. 2020; 33(6):566-573. 